\title{
The effect of corporate image on the formation of customer attraction
}

\author{
Reza Koohjani Gouji, Reza Taghvaei* and Hossein Soleimani
}

Department of Marketing, Malayer Branch, Islamic Azad University, Malayer, Iran

C H R O I C L E ABS T RAC T

Article history:

Received January 5, 2016

Received in revised format

August 2, 2016

Accepted August 23, 2016

Available online

August 23, 2016

Keywords:

Corporate Image

Customer Attraction

Irancell Telecommunications

Services Company

\begin{abstract}
This paper examines the relationship of corporate image with customer attraction in Irancell Telecommunications Services Company in city of Ahvaz, Iran. The study uses a sample of 384 randomly selected people who use the firm's services. Measuring tools for corporate image and customer attraction are an 18-item questionnaire of Rampersad (2001) [Rampersad, H. (2001). 75 painful questions about your customer satisfaction. the TQM Magazine, 13(5), 341-347.] and a 14-item questionnaire of Geib (2005) [Geib, M. (2005). Architecture for customer relationship management to attract and retain customers approaches in financial services, IEEE, Proceedings of the 38th Hawaii International Conference on System Sciences.], respectively. Results of regression analysis showed that there was a significant relationship between corporate image and attracting customers in Irancell firm. In addition, dimensions of corporate image including experience, character, competence, quality, differentiation, cost, technology, and culture and cognition increase customer attraction to the company. On the other hand, component of culture has the most effect on attracting customers in this firm.
\end{abstract}

\section{Introduction}

During the last ten years, researchers of public relations have focused on customer relationship management. Consequently, both experts and researchers of public relations have tried so much to find a key concept to prove the effectiveness of public relations on corporate levels. Therefore, in contemporary public relations researches, corporate image has been recognized as a central and essential concept to represent public relationship value in an organization (Gharibi et al., 2012). Corporate image helps organizations achieve credibility and popularity. Corporate image has had various meanings and interpretations for organizations and companies; therefore, there have been various definitions of corporate image (Bonenr, 2007). In service industry, corporate image is an invisible property of the organization that is the result of a common social judgment made by beneficiaries who are influenced by the ability of organization to meet the expectations and create value for stakeholders (Faircloth, 2005). In terms of economics, corporate image is a reflection of the past 
actions, which represent the company's actual attributes (Gregory, 1991). As it is mentioned, making a positive and influential corporate image is very important for organizations, so that they spent time, sources and efforts to advertise their goods or services to represent a positive image and reputation of themselves. Or, for example, they participate in charities and welfare affaires to look for a responsible organization in ideas of people, socially. Despite this fact, image of service organizations is of the areas that have been considered less (Chan-Olmsted, 2006). In addition, organizations have understood that in order to achieve their great purposes, they not only have to increase the image and the credibility of their organizations, but also this attempt must be aligned with attracting and maintaining the customers. Therefore, it must be confirmed that nowadays, markets are restricted and customers are scarce, so those organizations that look for new methods and ways to have leadership of market under their control will be successful. Leading market is one of the most important success factors for customer-oriented organizations and methods of attracting customers through improved corporate image to customers (Tahvildari, 2011).

Nowadays, in competitive condition of market, identifying factors that have long-term competitive privileges for the organization is very important. Of course, these factors are limited to tangible ones, but the provided services by the organization help to increase the value of organizations by making differentiation mode that leads to not only customer attraction and its faithfulness, but also, more importantly, increase of organization image in market. Additionally, organization's image is considered as one of the main elements of getting competitive advantage (Ranjbarian et al., 2011). Corporate image is a long-term investment and property to promote the ability of the planners, executives and employees in improving the delivery of effective services, according to the organization's service, in line with corporate goals (Venable et al., 2003). However, this depends on attempts and performance quality of staffs. Many communities, despite having rich natural resources, are not able to use them due to lack of qualified and competent human resource and pass the life by hardship. Other nations, despite the lack of natural resources, have welfare and comfort as a result of having trained and appropriate manpower and with firm strides, they track their progress over. This good manpower can act by his/her complete capability, if he/she is aware of the effect of his/her activity on image of the organization (Oh $\mathrm{Mi}, 2000)$. In service organizations, services are produced and consumed at the same time, therefore, service staffs are both providers of services and consumers of them. Also, their activities connect the organization to the customers and purpose of such activities is to attract and maintain customers through the realization of the promises that have been given (Berry, 1995). Therefore, examining effective factors on attracting and customer retention is essential and inevitable for non-profit organizations. Often, we have ignored the fundamental point that basically, not only must service provision be done for satisfaction of customer, but also it is suitable that all facilities and material and physical resources will be applied in order to provide complete customer satisfaction to attract and retain them (Tahvildari, 2011). Attracting and retaining customers is one of the primary concerns for companies providing mobile services. Technology development and growth in the number of mobile operators intrigue customers to use services of the other operators. Meanwhile, some of the subscribers tend to change their mobile operator or use one of them more than the other. As a result, income of operators will be changed. Therefore, attracting subscribers is very significant for mobile operators (Nazari, 2013). Increasing development of communication services, promotion of their quality and also attention to special services that help users in their daily activities cause neither of companies providing mobile services to be in secure margin. In such a climate, maintaining the available customers and increasing their numbers in a market that is very much competitive are hard jobs and increase costs of keeping the available customers and increasing their numbers. Therefore, despite the great importance of corporate image, its effect on development and success of telecommunication companies, intense competition between telecom companies in terms of customer acquisition and satisfaction and achieving their corporate goals, this subject has not been studied very much and it can be said that this subject has been somehow neglected. According to previous studies, a research vacancy for examining the relation between corporate images with customer attraction in Irancell communications Services Company seems urgent and profitable. Therefore, according to aforementioned explanations about corporate 
image and customer attraction in Irancell communications Services Company, here is the question: can corporate image be effective on attracting customers of Irancell communications Services Company in Ahvaz?

\section{Literature Review}

\subsection{Concepts and Theories}

\subsubsection{Corporate Image}

Corporate image, in the view of strategic management, is a collective vision and a collective image of the multiple beneficiaries of an organization or a company (Venable et al., 2003). Corporate image is a representation of past actions and perspectives of the future. Corporate image is one of the most important strategic and valuable properties that a company or an organization can have (Chan-Olmsted, 2006). It is, also, an evaluation of organization by beneficiaries during time (Oh Mi, 2000). Image of an organization means perceived confidence about the ability and the desire to constantly deliver what is promised and provides a great benefit for both customers and companies. In fact, purchasing a valid brand means that the efforts of merchants, due to extended probability of accepting the message, would be more affordable. As a result, sales of companies will increase following customer's referrals, and repeated purchase (Chan-Olmsted, 2006). In spite of increasing knowledge about the importance of credibility and image of organization as its specifics, a few studies have reviewed that how corporate image and credibility will affect customer's choice behavior. Understanding the combined mechanism of corporate credibility and image in formation of purchase tendency will be important and influential for advertisers and merchants, because it provides essential guide for development of brand positioning, through more appropriate advertising and brand-making strategies. Moreover, there is a restricted information about whether the available conditions in compound mechanism of credibility and corporate image are weaker or stronger or not in customer's decision-making among various groups of products (Martinson, 2007).

Components of corporate image: Despite numerous attempts to define the corporate image, a few researchers have tried to analyze principle and essence of the concept. Perhaps, Avenarius (1993) is one of the few people who has defined corporate image in accordance with its hidden components and elements. According to Lee (2004), corporate image is made of three components:

1: the rate of being known: that is requisite for each corporate image; it means that those organizations that are known can have effective roles.

2: fame: is a more active estimation and evaluation of society for which the base is history of organization or background of its performance.

3- (Brilliant and) special history and literature: by which each organization can be distinguished from its rival firms (that may have any equal fame)

There are five factors that have the ability and capability to affect customers' perceptions and interpretations of corporate reputation of service firms, including:

1: corporate identity, 2- fame, 3- form of servicing, 4- physical environment, 5 employees in contact (face to face) with customers.

\subsubsection{Customer attraction}

Customer attraction is a term to describe how to manage hyperactive communication with customers. Customer attraction is all the components within an organization that are intelligently associated with the customer. Customer management procedures connect all the components to each other with the support of operational roles and technical business. Due to the nature of business, attraction of customer 
can be complicated. Many of operations and daily activities of business must deal with customers; therefore, providing systems that can improve these tasks is vital for achieving success.

Customer attraction consists of business process, technology and required roles to manage customers in various steps of life cycles of organizations. It is beyond these departments and to a certain extent each separate corporate unit. A vendor using customer attraction in a corner of country does not need to access to all the information associated with the current position of selling of a customer in another corner of the country. However, they may need to access data related to customer or client's satisfaction to help to conclude a deal. The power to provide information at an accurate time is often the distinguishing key of a successful system (Cunningham, 2009).

Attracting customer means creating incentives to attract existing customers as well as the creation of a system for interacting with lost customers. Kotler (2984) believes losing profitable customers efficiently impacts on profitability of the organization. A group considers attraction of customers as strategy, some as a technology, some other as a process and some as information systems (Thompson, 2004). Here are a few of definitions of customer attraction:

"Attracting customer is a term for a collection of methodologies, processes, software packages and systems that help institutes and organizations in effective management and structured communication with customers" (Burnett, 1992). Attracting customers means creation and maintenance of a personalized relation with profitable customers through appropriate use of information technology and communications (Payne, 2000; Wilde et al., 2011). Attracting customers is a process consists of monitoring customer (e.g., collecting their suitable data), management and evaluation of the data, and finally creating a real advantage out of extracted information in the interaction with them (Hampe \& Swatman, 2002). Attracting customer is a comprehensive strategy of business and marketing that integrates technology, processes and all business activities around customer (Feinberg \& Romano, 2003).

\subsubsection{Emergence fields of attracting customers}

Patricia Siebold, an old fan of supporting systems and a fan of automatizing these systems, is one of the leaders in customer attraction. He has listed three following principles in his last book (Elahi \& Heidari, 2012):

- Customers are under control

- Communication with customers is valuable and

- Customer's experience is an important topic

Siebold believes and strongly states that customers are under control. Referring to the revolution in the music industry, which led this industry to have a tendency toward customers, he states that power of customers and users, nowadays, is non-stoppable. Revolutions made by some companies such as Napster (provider of music or singing files) created a demand that could not be ignored in music industry. Today, these customers have made a completely new series of demands (such as recordable CDs, downloading mobile broadcast) that did not exist in the past.

Siebold believes the relationship between customer and provider must be at the top of the priority list of organization. Attracting customers requires costs and keeping these relations is even more costly. However, if these relationships are not kept, the cost of attracting customers or replacing new customers will be much more expensive. This capital is called customer. Changing customers to a valuable commodity must look as a clear duty to each person. But, even in the United States where services to customers are like high standards, many companies have faced with failure in this respect. Sometimes, the failures result from lack of attention, and sometimes they are due to lack of coordination in system 
of attracting customer. Comprehension of full experiences of customers is much more than making a good product or providing accurate information for people who are in relation with customers. However, experiences of customers, mentioned by Siebold in his book, are essential for success of an organization. Quality and services are able to change the brand by customers (Salarzehi \& Amiri, 2011).

\subsubsection{Principles of attracting customers}

Applicable processes and programs for attracting customers are as the following according to basic principles:

Targeting individual customers: one the principles of attracting customers is the fact that customers have numerous choices and each client needs his/her own services. Attracting customers treats each customer individually because of being based on the philosophy of customization and personalization. Customization means that the content and services offered to the customer have to be designed according to their preferences and behaviors. This action makes comfort for customers and increased costs to the seller.

Attracting and retaining customer's loyalty through personal contact: when customization happens, organizations have to maintain this relationship. Continuous contacts with customer- especially when the contacts are designed to satisfy preferences- can lead to loyalty (Hamidizadeh et al., 2009). Customer's choice based on the concept of customer's lifetime value: this principle is considered that various customers have different values for the organization; therefore the most profitable customers must be attracted and maintained. Through differentiation, an organization can allocate its limited resources for better returns. To sum up, customization of products, customer loyalty and their selection based on the concept of lifetime value are the basic principles of customer relationship management (Wilde et al., 2011).

\subsection{Research Background}

Bagheri and Erfanifar (2010) reviewed the design of model of effective components on corporate image of University of Imam Sadeq (AS). Components such as identity and Culture of University, graduates, selectivity and other arrival factors, reputation and particular history, features and functionality of different parts, the physical environment and symbols, staff in contact with external audiences and media coverage of news and events have been identified as the most important effective factors on the image of this university.

Farahmand Sabet (2011) examined the relationship between corporate reputations with customers' behavioral intentions in the Novin Economy Bank. The results of the study indicated that first; the model had a good fitness. Second, corporate image and customer's behavioral intentions had a significant relation. Third, corporate image has relation with customer's behavioral intentions through the components of Customer's recognition, customer's commitment and customer's confidence. Shams Zaharias (2011) examined and determined the effective features of attraction and survival of customers. The findings showed that two variables of the use of the service and speed of service delivery had positive effects on the probability of attracting customers. The amount of customer's satisfaction cost of change and amount of service use have positive effect of the probability of customer's loyalty. Haghighi et al. (2012) reviewed the effect of relational marketing tactics on attraction and loyalty of customers from the perspective of customers of Irancell Company. Data analysis showed that the company had been successful in implementing some of the tactics and at the significance level of 90 percent had been able to have the customers' satisfaction and trust; as a result, it could retain them and changed them into loyal customers. 
Khajeh (2013) studied perspective of social identity of brand and its effect on attracting customers and developing loyalty to the brand in Irancell Company in Golestan province. The results were indicative of the fact that the identity of the brand, indirectly and through the variables of comprehended value, satisfaction and confidence, has positive effect on attracting customers and loyalty to the brand. In addition, this study concluded that when perspective of social identity of brand is compounded with other available perspectives can be useful it is possible to predict the mechanisms of loyalty to the brand.

Kandy (2007) examined the elements affecting on corporate image. The results indicated that two main elements show the image of the organization including emotional and functional elements. Functional element is associated with tangible features, which could be easily measured and emotional element is related to psychological aspects which are identified by emotions and attitudes about organization. These emotions are created because of various experiences with organization and processing the information on the features that are the functional indexes of the image.

Keropyan and Lafuente (2014) studied the programs affecting on attracting and retaining customers in the telecom market. The results of study were indicative of the importance of telecommunication (mobile) market in which tendency of customers to change the company is very high. Therefore, mobile telecommunication companies must provide special programs and services for their customers to satisfy them and prepare special services for each group of customers to increase number of attracted customers. Izogo (2015) examined the factors affecting on attracting and retaining customers in telecommunication market. In this study, 138 users of telecommunication services were used to gather data. The results showed that attracting and retaining customers was a process-based structure which starts from Service Assurance by the Organization and finally, leads to attracting and retaining customers.

\subsection{Conceptual model of research}

Conceptual model of study has been shown in Fig. 1:

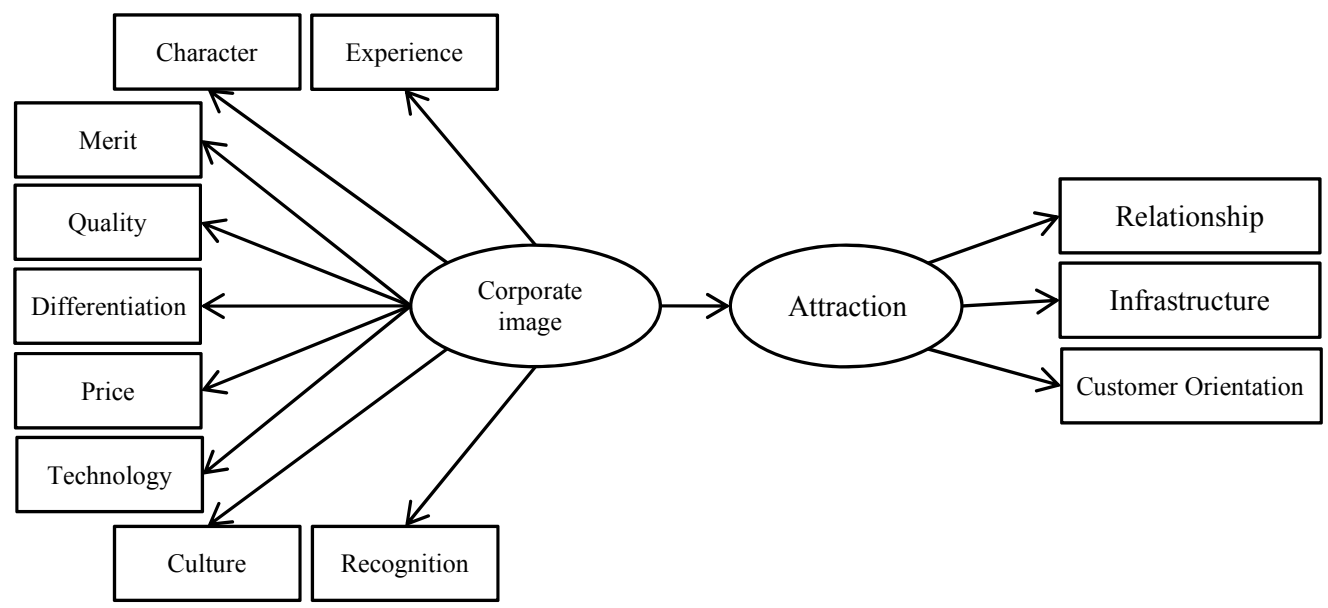

Fig. 1. Conceptual model of research

\subsection{Research hypotheses}

\subsubsection{Main hypothesis}

There is a significant relationship between corporate image and attraction of customers in Irancell Telecommunications Services Company in Ahvaz, Iran. 


\subsubsection{Secondary hypotheses}

1- There is a significant relationship between experiences and attraction of customer in Irancell Telecommunications Services Company in Ahvaz, Iran.

2- There is a significant relationship between character and attraction of customer in Irancell Telecommunications Services Company in Ahvaz, Iran.

3- There is a significant relationship between merit and attraction of customer in Irancell Telecommunications Services Company in Ahvaz, Iran.

4- There is a significant relationship between quality and attraction of customer in Irancell Telecommunications Services Company in Ahvaz, Iran.

5- There is a significant relationship between differentiation and attraction of customer in Irancell Telecommunications Services Company in Ahvaz, Iran.

6- There is a significant relationship between price and attraction of customer in Irancell Telecommunications Services Company in Ahvaz, Iran.

7- There is a significant relationship between technology and attraction of customer in Irancell Telecommunications Services Company in Ahvaz, Iran.

8- There is a significant relationship between culture and attraction of customer in Irancell Telecommunications Services Company in Ahvaz, Iran.

9- There is a significant relationship between recognition and attraction of customer in Irancell Telecommunications Services Company in Ahvaz, Iran.

\section{Methodology}

The present study is applied respective to purpose; descriptive correlational regarding the method; and a quantitative study due to its method to gather data. Population of study includes entire customers of Irancell Telecommunications Services Company in Ahvaz, Iran. Because of lack of availability of all the customers, the population is considered unlimited. The sample was estimated to be 384 using sampling has been random sampling technique.

In the current study, data was gathered by questionnaire and field method. Measurement tool for corporate image is Rampersad (2001) corporate image questionnaire that has 18 fine-option questions. It is scored as $1=$ very little, $2=$ little, $3=$ fair, $4=$ high, $5=$ very high. The questionnaire has nine dimensions of "Experience, character, competence, quality, differentiation, cost, technology, culture and cognition" that each of them are marked with two questions. Validity and reliability of this questionnaire in other study (2001) were 0.81 and 0.89 , respectively. Tool to measure attraction of customer is the 14- item questionnaire of Geib (2005). This questionnaire has three dimensions of: expanding customer relationships, infrastructure and customer orientation. Scoring in this questionnaire is as option $1=$ very little, $2=$ little, $3=$ fair, $4=$ high, $5=$ very high. On the other hand, validity and reliability of the questionnaire has been 0.89 and 0.83 , respectively. Due to being standard, and being applied in various researches as well as idea of experts, the validity of questionnaire is accepted. In addition, using Cronbach's Alpha on 30 people of sample, reliability for the questionnaires is measured in Table 1

Table 1

Cronbach's Alpha coefficients

\begin{tabular}{cccc}
\hline Variables & Cronbach's Alpha coefficient & Variables & Cronbach's Alpha coefficient \\
\hline Corporate image & 0.81 & Price & 0.8 \\
Attraction & 0.78 & Technology & 0.75 \\
Experiences & 0.74 & Culture & 0.74 \\
Character & 0.72 & Recognition & 0.76 \\
Merit & 0.71 & Relationship & 0.75 \\
Quality & 0.73 & Infrastructure & 0.81 \\
Differentiation & 0.74 & Customer orientation & 0.77 \\
\hline
\end{tabular}


The results of Table 1 show that Cronbach's alpha of the questionnaires and their dimensions are more than 0.7. Therefore, the questionnaires have acceptable reliability and therefore, they have the capability of generalizability in the population under study.

In inferential statistics and to estimate the results of assumptions, Kolmogorov-Smirnov (KS) Normal distribution of data and to study the normal distribution of data, Pearson correlation was used. The relationship between the two variables with small scale and multiple regression to predict the criterion variable based on the predictor variables was analyzed by SPSS software version 22.

\section{Findings}

\subsection{Normality of variables}

First, prior to examining the hypotheses of study, it is essential to evaluate normality of variables by Kolmogorov-Smirnov (KS) test. Therefore, Table 2 examines the normality of variables

Table 2

Variables normality

\begin{tabular}{cccccc}
\hline variables & Z Statistics & Level of significance & variables & Z Statistics & Level of significance \\
\hline Corporate image & 0.884 & 0.215 & Differentiation & 1.131 & 0.101 \\
Attraction & 0.316 & 0.627 & Price & 0.719 & 0.319 \\
Experiences & 0.614 & 0.423 & Technology & 1.136 & 0.099 \\
Character & 1.03 & 0.119 & Culture & 0.935 & 0.188 \\
Merit & 0.436 & 0.557 & Recognition & 0.812 & 0.27 \\
Quality & 1.153 & 0.092 & & & \\
\hline
\end{tabular}

According to the results of Table 2, it can be concluded that the significance levels of all the variables is more than 0.05 . Therefore, the hypothesis of $\mathrm{H}_{0}$ is rejected and data of the above variables is normal. So, normality of the mentioned variables justifies using parametric tests to deduct the hypotheses of study.

\subsection{A review of hypotheses of study}

To examine the bilateral relation between variables of each hypothesis, correlation test is used. The results are stated in Table 3.

Table 3

$\underline{\text { Results of bilateral relation between hypotheses of study }}$

\begin{tabular}{cccccc}
\hline Hypothesis & Independent variable & Dependent variable & $\begin{array}{c}\text { Correlational } \\
\text { coefficient }\end{array}$ & $\begin{array}{c}\text { Level of } \\
\text { significance }\end{array}$ & Result \\
\hline Main & Corporate image & Attraction & 0.507 & 0.001 & $\mathrm{H}_{0}$ Rejected \\
1 & Experiences & Attraction & 0.348 & 0.001 & $\mathrm{H}_{0}$ Rejected \\
2 & Character & Attraction & 0.353 & 0.001 & $\mathrm{H}_{0}$ Rejected \\
3 & Merit & Attraction & 0.323 & 0.001 & $\mathrm{H}_{0}$ Rejected \\
4 & Quality & Attraction & 0.257 & 0.001 & $\mathrm{H}_{0}$ Rejected \\
5 & Differentiation & Attraction & 0.267 & 0.001 & $\mathrm{H}_{0}$ Rejected \\
6 & Price & Attraction & 0.317 & 0.001 & $\mathrm{H}_{0}$ Rejected \\
7 & Technology & Attraction & 0.288 & 0.001 & $\mathrm{H}_{0}$ Rejected \\
8 & Culture & Attraction & 0.346 & 0.001 & $\mathrm{H}_{0}$ Rejected \\
9 & Recognition & Attraction & 0.315 & 0.001 & $\mathrm{H}_{0}$ Rejected \\
\hline
\end{tabular}

About all the variables, the level of significance attained from Pearson test is less than 0.01 which shows there was a significant relationship between two variables with $99 \%$ level of confidence. In addition, positive correlation coefficient indicates that the more independent variable is, the more the amount of customer's attraction is. Therefore, it can be claimed that the null hypothesis is rejected and the researcher's hypothesis can be replaced as a new hypothesis. 


\subsection{Prioritizing the influence of corporate reputation on customer attraction}

To confirm prioritizing the influence of corporate reputation on customer attraction, Multiple Regression analysis in an Enter method is applied. To conduct this test, first, presupposition of regression analysis must be performed in order to make the results of regression analysis deductible.

1- Presuppositions of correlation between the criterion variable and independent variables (this presupposition is examined and confirmed in the first to ninth secondary hypotheses).

2- Presupposition of explanation of model: in this presupposition, it must be considered that whether independent variables have the ability to explain (the mean effect of independent variables on criterion variable) the criterion variable.

3- Presupposition of a review of linear relation between independent variables and criterion variables in which ANOVA test is applied.

\subsubsection{Model explanation}

Table 4 explains the amount of clarification of regression model in prioritizing the effects of corporate image dimensions.

\section{Table 4}

Regression model explanation

\begin{tabular}{cccc}
\hline $\mathrm{R}$ & $\mathrm{R}$ square & Adjusted square of R & Durbin Watson \\
\hline 0.544 & 0.296 & 0.278 & 1.537 \\
\hline
\end{tabular}

According to the results of Table 4, it is clearly seen that adjusted R-square is equal to 0.278 , which means about $28 \%$ of changes in the variable of customer attraction is described by changes in dimensions of corporate image. In addition, as the amount of Durbin-Watson is between 1.5 and 2.5 so the supposition of independence between error terms is accepted.

\subsubsection{Linear relation}

Table 5 reviews linear relationship between criterion variable with predictor by ANOVA test.

Table 5

Linear relation between criterion and predictor variables

\begin{tabular}{cccccc}
\hline Model & Sum of squares & Freedom degree & Mean of square: & Statistic F Level of significan \\
\hline Regression & 36.926 & 9 & 4.103 & 17.507 & 0.001 \\
The remaining & 87.651 & 374 & 0.234 & - & - \\
Sum & 124.577 & 383 & - & - & - \\
\hline
\end{tabular}

\subsubsection{Model Function}

Since all three conditions for using multivariate regression were taken into consideration, a function must be provided to show the amount of prediction of the predictor variable in direction of criterion variable. Therefore, Table 6 represents regression coefficients. According to the results of Table 6 , it can be mentioned that the level of significance of test is a fixed amount less than $0.05 \%$. Therefore, the supposition of alpha being equal to zero is rejected and the fixed amount effects on criterion variable, so that it can participate in non-standard coefficients equation. In addition, in significance level of test, coefficient levels of dimensions of experience, character, price, culture and cognition are less than 0.05 , therefore, they are suitable to enter to standard coefficient equation or in the other words, they can affect on criterion variable. While significance levels of competence, quality, differentiation and technology are higher than 0.05 and cannot be used in the equation. According to the above explanation, standard and non-standard coefficients function is as following: 
According to above function, it can be concluded that due to the external factors, the dimensions of experience, personality, prices, culture and cognition can predict the rate of customer attraction. While the dimensions of competence, quality, differentiation and technology are not able to predict variable of attracting customers. Also, according to beta coefficient in the culture, it can be stated that culture has the greatest impact on customer attraction in Irancell Telecommunications Services Company in Ahvaz and then the dimensions of price, experience, knowledge and character are after culture.

Table 6

Regression coefficients

\begin{tabular}{|c|c|c|c|c|c|}
\hline & \multicolumn{2}{|c|}{ Non-standard coefficients } & \multirow{2}{*}{$\frac{\text { Standard coefficient }}{\text { Beta }}$} & \multirow{2}{*}{$\begin{array}{c}\text { statistic } \\
\mathrm{t}\end{array}$} & \multirow{2}{*}{ Level of significance } \\
\hline & $\mathrm{B}$ & The standard error & & & \\
\hline Constant & 1.025 & 0.142 & - & 7.213 & 0.001 \\
\hline Experiences & 0.077 & 0.032 & 0.128 & 2.39 & 0.017 \\
\hline Character & 0.073 & 0.036 & 0.114 & 2.053 & 0.041 \\
\hline Merit & 0.067 & 0.034 & 0.103 & 1.948 & 0.052 \\
\hline Quality & 0.015 & 0.031 & 0.025 & 0.488 & 0.626 \\
\hline Differentiation & 0.01 & 0.032 & 0.017 & 0.328 & 0.743 \\
\hline Price & 0.116 & 0.031 & 0.176 & 3.785 & 0.001 \\
\hline Technology & 0.001 & 0.031 & 0.00 & 0.025 & 0.98 \\
\hline Culture & 0.148 & 0.033 & 0.209 & 4.509 & 0.001 \\
\hline Recognition & 0.077 & 0.031 & 0.125 & 2.507 & 0.013 \\
\hline
\end{tabular}

\section{Conclusion and recommendations}

\subsection{Discussion and conclusion}

In this study, the relationship between organizational image with customer attraction in Irancell Telecommunications Services Company was studied. The results showed that there was a positive and significant relationship between corporate image and customer attraction. In addition, according to comparison between the results of the present study and other conducted studies, it can be mentioned that there is an alignment between results of this study and results of studies of Alizadeh Zavarom et al. (2011), Ranjbarian (2011), Farahmand Sabet (2011), Shams Zahraei (2011), Ahmadzadeh (2011), Daneshfar (2012), Haghighi et al. (2012), Hassanzadeh Khatir (2014) and Keropyan and Gil-Lafuente (2014).

By the analogy of the main hypothesis of study with the results of previous studies, it can be concluded that corporate image will cause customer attraction including existence of incentives to attract potential customers, customer interaction system, bilateral interaction with the customer, a long-term relationship with the customer, a formal system for customer identification, senior managers' support of related activities to customer, remembering the names of customers by company members, the importance of the problem of customers for the company, attention to the changing needs and demands of customers, timely and accurate customer service, respond to the enterprise customer feedback and etc. to increase. In fact, better image the organization has among people, the more the level of confidence and trust of customers will be and makes the customers attracted to the services of company. Moreover, suitable image of organization makes the organization always be thinking about attracting customers and therefore, conducts some activities in this respect such as creating systems and accurate planning to pave the way of attracting customer by promoting the level of his satisfaction. Attracting customers can take place through channels like creating constant and effective relations with customers, managing relations with them, considering infrastructures in the organization for permanent relation of company with customers and also conducting tasks of company around the needs and demands of customers under the title of "customer- orientation".

By the analogy of the first secondary hypothesis of study with the results of previous research, it can be concluded that experience including the suitability of the company's employees work history, 
desirability of employment history of company, utilization of their experiences during responsiveness customer, customer greater use of the experience and knowledge of employees, etc. can increase attraction of customer. Because experience and learning from the previous experiences can be considered as an invisible but beneficial capital that makes the customer relies on the rich history of the company and makes use of the knowledge of company to meet his needs. On the other hand, experience of the company can create a good image and reputation for company that besides promoting level of knowledge of staffs can be considered as a credit making peace and comfort for customers while using the services.

By the analogy of the second secondary hypothesis of study with the results of previous research, it can be concluded that some characters including the appropriateness of public relations with customers, employees being patient toward customer's needs, persistence of staff to dealing with unforeseen issues, ability to solve conflicts among employees, etc. can increase attracting customers. Because the better and the longer relationship the company can make with its customers, the more constant the customers think about the company and the more attracted he/she will be. On the other hand, appropriate characteristics of the staffs of company can increase the level of dependence of customer to the company, because the more aligned behaviors of customers with social and cultural norms, the more relaxed the customer is. As a result the ground for his/her attraction will be provided. In the other word, characteristics associated with consistency of the staffs and their high abilities in unpredictable situations can attract customer's confidence in the company.

By the analogy of the third secondary hypothesis of study with the results of previous studies, it can be concluded that competence including high levels of professional skills and special abilities of employees, companies using modern methods, increasing knowledge and awareness of staffs through learning, high levels of employee's empowerment when dealing with issues and problems, their problem solving ability, etc. can grow customer's attraction. Because competence and ability of staffs regarding organizational issues cause the customer to rely on the company more in order to meet his/her needs, therefore, the level of his/her satisfaction and loyalty will increase. Specialized skills of staffs promise to provide better services to the customer by the company and so it will be able to attract and retain customers.

By the analogy of the forth secondary hypothesis of study with the results of previous studies, it can be concluded that quality including services provided to customers being up-to-date, optimized data services, high quality and quantity of provided services, the customer service standards being in line with his/her needs, etc. can enhance customer's attraction, because quality of services in the company is extracted from sufficient knowledge and experience in the form of importance of customers' needs for the company. When customer feels the provided services have a good quality, he/she will understand knowledge and awareness of the company and importance of his/her interests for the company, as a result, he/she will be more attracted to the services. Quality can lead to satisfaction of customer and satisfied customer always tries to get his/her previous experiences from the company and therefore, will be attracted to the services of the organization.

By the analogy of the fifth secondary hypothesis of study with the results of previous research, it can be concluded that differentiation including provision of differentiated services to customers from different social classes, provision of more and better services for customers, differentiation of customer service rather than the other competitors, difference in providing services for customers regarding quality and quantity in comparison with other competitors, etc. can increase customers' attraction; because differentiation can make a feeling for the customer that the company has acted better and more different than the others and so it can make a more desirable and better experience for the customer. Differentiation causes customer to have a modern and new service that has not earned any service like that in other companies. Therefore, customer will be attracted to the company for getting such a feeling. Differentiation makes the services to be better, in the other word, more qualified and cheaper for 
customer, so that customer always keeps this difference in his/her mind and will be loyal to the company, and finally will be attracted to the company.

By the analogy of the sixth secondary hypothesis of study with the results of previous research, it can be concluded that price including proportionality between payments of customer and received services, low cost of services compared to other competitors, reasonable prices for services of company, etc. can enhance customer's attraction; because the more provided services for customer and payments of customer have balance and alignment, the better customer can handle costs of received services and so will be attracted to the company. Customer must believe that costs that he/she pays for the received services will both meet his/her needs and costs are balanced with the received services. In this case, the customer can have tendency toward the company. Therefore, price plays in important role in this respect. An extremely high cost or an excessively low cost can make customer not to have a good idea about the received services and so he/she may decide to abandon the company and its services.

By the analogy of the seventh secondary hypothesis of study with the results of previous studies, it can be concluded that implementation of some technology features including using modern technologies in the company, appropriateness of processes of relation with customer, having modern and updated facilities and equipment in the company, etc. can increase customer attraction; because updated equipment and modern facilities in the company can be retrieved from high level of technology in the company and so it can cause processes within or outside the organization to be performed faster and with a better quality. Finally, useful effects will be provided for customer. Modern technology can minimize humans' errors and makes the services to be prepared for customers with the best accuracy and in the shortest time. Consequently, it can be transfer a sense of comfort and ease to the customer and intrigue him to use the services more.

By the analogy of the eighth secondary hypothesis of study with the results of previous studies, it can be concluded that culture including the constructive atmosphere in the company, an atmosphere of intimacy between employees and customers, respecting the rights of clients in the enterprise, the pursuit of customer problems to solve them by employees of the company, understanding the customer's demands by employees, etc. can increase attracting customers; because organizational culture makes the level of moral principles and professional behavior of staff to increase and the staffs allocate themselves to address the needs and problems of customers. High culture in company promises an effective and dynamic atmosphere in which customer feel calm and peace of mind and will be sure that staffs with high organizational culture are always trying to solve his/her problem, therefore, the customer will be attracted to the company.

By the analogy of the ninth secondary hypothesis of study with the results of previous studies, it can be concluded that cognition including staffs' high understanding of the client's actual needs, careful planning in order to meet customer needs, provision of useful information to customers, diversity in services, awareness of employees of their job status, etc. can improve customer attraction; because staffs' cognition gives a feeling to customer that company pays enough and essential attention to his/her needs and demands and issues of customers are considered very important to the company. Therefore, customer does not feel being alone and will be attracted to the company more than before. In the other word, staffs' accurate cognition of customer's needs cause the services to be compatible with customer's demands and so customer can be highly satisfied and it provides the ground for attracting customer to the company.

\subsection{Recommendations}

According to the main hypothesis of research and relationship between corporate reputation with attracting customer, it is recommended to all managers of Irancell Telecommunications Services Company in Ahvaz that for promoting the level of working character of staffs, they must increase the 
extent of their knowledge in the field of corporate reputation including special attention to the background of employees, increasing employee personality, organizational learning, paying attention to better quality services, comparing their services with other competitors, balanced price, taking advantage of the best equipment, raising the level of organizational constructive climate to involve employees in the organization's activities in order to know them better.

According to the first secondary hypothesis regarding research and experience with customers, it is recommended to all managers of Irancell Telecommunications Services Company in Ahvaz to increase the rate of attracting customer by hiring employees with a history of relevant work experience and utilization of employees during organizational decisions.

According to the second secondary hypothesis and the relationship of personality with attracting customers, it is recommended to all managers in Ahvaz Irancell Telecommunications Services Company to increase rate of customer attraction by creating good public relations with the customer and managing conflict in organizations.

According to the third secondary hypothesis and the relationship of competence with attracting customers, it is recommended to all managers in Ahvaz Irancell Telecommunications Services Company to increase rate of customer attraction by raising the level of specialized skills and abilities of staff and using modern methods.

According to the forth secondary hypothesis and the relationship of quality with attracting customers, it is recommended to all managers in Ahvaz Irancell Telecommunications Services Company to increase rate of customer attraction by updating provided services to customers and raising quality and quantity levels of provided services.

According to the fifth secondary hypothesis and the relationship of differentiation with attracting customers, it is recommended to all managers in Ahvaz Irancell Telecommunications Services Company to increase rate of customer attraction by providing more and more convenient services to customers and being different in the delivery of services to customers rather than other competitors.

According to the sixth secondary hypothesis and the relationship of price with attracting customers, it is recommended to all managers in Ahvaz Irancell Telecommunications Services Company to increase rate of customer attraction by the fitness between customer's payments and incoming services and reasonable prices for services companies.

According to the seventh secondary hypothesis and the relationship of technology with attracting customers, it is recommended to all managers in Ahvaz Irancell Telecommunications Services Company to increase rate of customer attraction by taking advantage of new technologies in the enterprise and use of new and up to date equipment and facilities in company.

According to the eighth secondary hypothesis and the relationship of culture with attracting customers, it is recommended to all managers in Ahvaz Irancell Telecommunications Services Company to increase rate of customer attraction by making a constructive atmosphere in the company and respecting the rights of customers and employees in the company.

According to the ninth secondary hypothesis and the relationship of cognition with attracting customers, it is recommended to all managers in Ahvaz Irancell Telecommunications Services Company to increase rate of customer attraction by careful planning in order to satisfy customer needs and raise the awareness of employees through in-service training, 


\section{References}

Ahmadzadeh, S. (2011). The relationship between service quality, perceived value, customer satisfaction and loyalty in terms of subscribers MTN (Case Study: West Azerbaijan province). Master's thesis, Semnan: Semnan University.

Alizadeh Zavarem, A., Fallah, M. \& Eslami, Gh. (2011). Injection study in brand image. Management Journal, 5(2), 88-65.

Avenarius, H. (1993). Introduction: Image and public relations practice.Journal of public relations research, 5(2), 65-70.

Bagheri, M.H. \& Erfanifar, A. (2010). Factors affecting corporate image design of Imam Sadeq. Journal of Management, 4(2), 77-43.

Berry, L. L. (1995). Relationship marketing of services-growing interest, emerging perspectives. Journal of the Academy of Marketing Science, 23(4), 236-245.

Bonenr, C. (2007). Image is all: Deregulation, restructuring and reputation in the natural gas industry, American Gas.

Burnett, K. (1992). Strategic Customer Alliances: How to win, manage, and develop key account business in the 1990s. London, Pitman.

Chan-Olmsted, S. M. (2006). Competitive strategy for media firms: Strategic and brand management in changing media markets. Routledge.

Compdrsad, L. (2001). Corporate reputation: our role in sustaining and building a valuable asset. Journal of Advertising Research, 45(3), 5-29.

Cunningham, J. M. (2009). Customer Relationship management: Wiley company. Oxford United Kingdom. Available at: www.capstoneideas.com.

Daneshfar, Z. (2012). Celebrity organizational citizenship behavior from the perspective of the customer relationship with clients in Iran Insurance Company. Master's Thesis, School of Accounting and Management, Tehran Allameh Tabatabai University.

Elahi, Sh. \& Heidari, B. (2012). Customer relation management. $3^{\text {rd }}$ ed., Tehran: business publishing company (In Persian).

Izogo, E. E. (2015). Determinants of attitudinal loyalty in Nigerian telecom service sector: Does commitment play a mediating role?. Journal of Retailing and Consumer Services, 23, 107-117.

Faircloth, J. B. (2005). Factors influencing nonprofit resource provider support decisions: applying the brand equity concept to nonprofits. Journal of Marketing Theory and Practice, 13(3), 1-15.

Farahmand Sabet, M. (2011). The relationship between organizational reputation with customers' behavioral intentions in the New Economy Bank. Master's Thesis, School of Accounting and Management, Tehran Allameh Tabatabai University.

Feinberg, J., \& Romano, C. (2003). Electronic customer relationship management revising the general principles of usability and resistance-an integrative implementation framework. Business Process Management Journal, 9(5), 340-359.

Fjermestad, J., \& Romano Jr, N. C. (2003). Electronic customer relationship management: Revisiting the general principles of usability and resistance-an integrative implementation framework. Business Process Management Journal, 9(5), 572-591.

Geib, M. (2005). Architecture for Customer Relationship Management to Attract and Retain Customers Approaches in Financial Services, IEEE (Proceedings of the 38th Hawaii International Conference on System Sciences).

Gharibi, M.; Koushki, A.R; Taleghani, G.R. \& Nargesian, A. (2012). The relationship between corporate image with that of Iran Khodro job. Journal of Organizational Culture Management, 10(1), 114-97.

Gray P., \& Byun, J. (2010). Customer Relationship Management, University of California, Available at: www.crito.uci.edu.

Gregory, J. (1991). Marketing Corporate Image. Chicago. NTC Business Books. 
Haghighi, M., Hosseini, S.H., Asgharieh Ahari, H., Arian, A., \& Darikandeh, A. (2012). The effect of relationship marketing tactics to attract customers, customer loyalty from the perspective of Irancell. Journal of Modern Marketing research, 2(4), 62-45.

Hamidizadeh, M.R.; Hajikarimi, A.A. \& Babaie Zagliki, M.A. (2009). Define and design the process model of customer loyalty (Case Study: private banks). Exploration Journal of Business Management, 1 (2), 170-133.

Hampe, J. F., \& Swatman, P. (2002). Customer Relationship Management. Institute Fur Wirschfs informatics.

Hassanzadeh Khatir, F. (2014). Telecommunications network service quality evaluation and satisfaction and attract citizens' case study: MTN Babylon area. Master's thesis, Faculty of Literature and Human Sciences, Tehran, Islamic Azad University, Tehran.

Kennedy, S. H. (1977). Nurturing corporate images. European Journal of marketing, 11(3), 119-164.

Keropyan, A., \& Gil-Lafuente, A. M. (2012). Customer loyalty programs to sustain consumer fidelity in mobile telecommunication market. Expert Systems with Applications, 39(12), 11269-11275.

Khajeh, I. (2014). Check their social identity and their effect on attracting customers and the development of brand loyalty (case? Christmas in Golestan province). Master's thesis, Faculty of Management and Accounting, Tehran Payam Noor University of Tehran.

Khanlari, A. (2006). A Conceptual Model for Measuring the Maturity of customer relationship management in IT organizations. Master's thesis, Tehran: Tehran University.

Kotler, P. (2003). Marketing Management. $11^{\text {th }}$ Edition. New Jersey; prentice Hall, 52.

Kotler, P., \& Anderson, A. R. (1987). Strategic Marketing foe Nonprofit Organizations (3 ${ }^{\text {rd }}$ ). Englewood Cliffs. NJ: prentice -Hall .

Lee, B. K. (2004). Corporate image examined in a Chinese-based context: A study of a young educated public in Hong Kong. Journal of Public Relations Research, 16(1), 1-34.

Lee, J. S., \& Back, K. J. (2010). Reexamination of attendee-based brand equity. Tourism Management, 31(3), 395-401.

Martinsons, M. G. (2008). Relationship-based e-commerce: theory and evidence from China. Information Systems Journal, 18(4), 331-356.

Nazari, P. (2013). The effect of relationship quality and customer loyalty among subscribers of MTN in Mashhad barriers to change. Master's thesis, Faculty of Economic and Administrative Affairs Management Group. Razavi Khorasan University of Mashhad.

Oh Mi, Y. (2000). South Korean attitudes toward foreign Subsidiaries of Multinational Corporations (MNCS): The halfpence of corporate image and country of origin image and the presence of Halo effect. Southern Illinois University.

Payne, A. (2000). Customer Relationship Management. Paper from the inaugural meeting of the London based customer relationship foundation. Available at; www.crm-forum.com.

Rampersad, H. (2001). 75 painful questions about your customer satisfaction. the TQM Magazine, 13(5), 341-347.

Ranjbarian, B.; Khajeh, E. \& Sadeghian, M. (2011). The role of corporate reputation on customer loyalty: A Case Study of four and five star hotels. Tehran: Fourth International Conference of Marketing Management.

Salarzehi, H. \& Amir, Y. (2011). Factors affecting the deployment process of customer relationship management in private banks. General Management Research, 4(12), 144-131.

Shams Zahraei, M. (2011). Determine the characteristics affecting the uptake and survival of bank customers in the Sinai with analytical CRM approach using data mining techniques. Master's Thesis, School of Management, Tehran, Islamic Azad University, Tehran.

Tahvildari, M. (2011). Analysis of factors affecting customers in export development bank of Iran. Banking and Economics, 45-46.

Thompson, B. (2004). What is CRM?. Available at: www.Custhelp.com.

Venable, B, T, G., Rose, M., \& Gilbert, W. (2003). Measuring the brand personality of nonprofit organizations. Advance in Consumer Research, 30(1), 77-89. 
Wilde, K. D. H., Hipper, C., Frielitz, S., \& Martin, T. (2011). Marketing E.CRM. Absatzwirchaft, Dusseldorf.

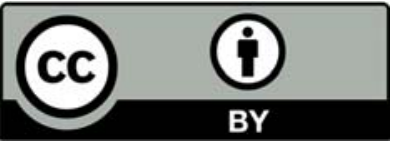

(C) 2016 by the authors; licensee Growing Science, Canada. This is an open access article distributed under the terms and conditions of the Creative Commons Attribution (CC-BY) license (http://creativecommons.org/licenses/by/4.0/). 